\title{
Clinical, Epidemiological and Demographic Profile of Patients Undergoing Holter (24 h) at a Health Center in Belém do Pará: a Retrospective Study
}

\author{
Fábio Benedito Filo Creão Garcia Pereira1, Lizandra Lujan Delpupo Trivilin', Marcia Rayssa \\ Farias Torres ${ }^{1, *}$

\section{ORCID IDs} \\ Pereira FBFCG (D) https://orcid.org/0000-0002-7001-8738 \\ Tivilin LLD (D) https://orcid.org/0000-0002-1760-1625 \\ Torres MRF (iD https://orcid.org/0000-0001-9785-4915
}

\begin{abstract}
Introduction: Dynamic electrocardiography by the Holter system can be divided into four major groups: evaluation of clinical manifestations related to the presence of altered heart rhythm; assessment of myocardial ischemia; risk assessment of future cardiac events; and therapeutic assessment. Objective: To identify the clinical, epidemiological and demographic profile that is associated with electrocardiographic changes in the 24-hour Holter in patients seen at the Escola do Marco Health Center in Belém do Pará, Brazil. Methods: We carried out a cross-sectional and retrospective study, with data from patients such as: clinical and electrocardiographic correlation, indications, tachyarrhythmias, bradyarrhythmias, medications in use, provenance, demographic data and behavior modification. All of the information was compiled in a standardized protocol. Results: The main electrocardiographic findings were: supraventricular and ventricular extrasystoles less than 1\% (reported in 71 and 57\% of patients, respectively). Conclusion: The 24-hour Holter still has an important role in the identification of patients with electrocardiographic changes. The main indications for the examination were to assess the severity of arrhythmia (32\%) and palpitation to clarify (23\%), and there were uncommon findings, but of great clinical importance and with statistical significance, such as almost three times more frequent nonsustained ventricular tachycardia in patients with heart failure, cardiac, symptomatic frequent extrasystole (> 3\%), more frequent atrial fibrillation in the elderly and men (60\%) and with underuse of anticoagulant therapy (20\%) due to non-diagnosis prior to the exam, and changes in the ST segment with a tendency in patients with systemic arterial.
\end{abstract}

KEYWORDS: Electrocardiography; Ambulatorial; Arrhytmias, Cardiac; Health profile.

\section{INTRODUCTION}

Several studies have shown that holter or dynamic electrocardiography is of fundamental importance for recording electrical signals from the heart and for documenting the occurrence of abnormal intermittent changes in cardiac electrical activity in the patients' routine, which may collaborate in the investigation and monitoring of cardiac arrhythmias, myocardial ischemia, autonomic disorders and abnormalities in the functioning of implantable cardiac devices ${ }^{1-3}$.

1. Universidade Estadual do Pará - Faculdade de Medicina - Departamento de Saúde Integrada - Belém (PA), Brazil. *Corresponding author: marciarayssa@outlook.com.br

Received: Aug 31, 2020 | Accepted: Jan 14, 2021 
This method is currently used under the following conditions:

- Confirmation of arrhythmias as a cause of symptoms occurring during daily activities (through clinical-electrocardiographic correlation);

- Detection of myocardial ischemia (by analyzing the ST segment and the T wave);

- Documentation of therapeutic efficacy or pro-arrhythmic effects of antiarrhythmic and anti-ischemic agents;

- Prediction of future cardiac events;

- Assessment of the autonomic nervous system (by analyzing heart rate variability);

- Evaluation of the functioning of implantable electrical cardiac devices (such as pacemakers, resynchronizers and implantable cardioverter defibrillators).

According to the Ministry of Health ${ }^{4}$, myocardial infarction (AMI) and stroke are the major contributors to deaths worldwide. In Brazil, they represent more than $30 \%$ of registered deaths. Also according to the Ministry of Health ${ }^{4}$, cardiovascular diseases are now the leading cause of death in developing countries and are expected to continue to be worldwide in the next decade.

Thus, it is understood that the simplification of the reading of the behavior and the geographical distribution of the demand of patients with cardiovascular diseases on the service network linked to the public health system in Belém, Pará, and, consequently, at the Centro de Saúde Escola do Marco makes it difficult to perceive and execute the best strategic decision to face it.

The objective of this study was to identify the clinical, epidemiological and demographic profile that is associated with electrocardiographic changes in the 24-hour holter in patients seen at the Cardiology Service of the Centro Saúde Escola do Marco, a health center in Belém, from September 2014 to September 2019.

\section{METHODS}

All data to raise the researched profile followed the precepts of the Declaration of Helsinki and the Nuremberg Code, respecting the Research Standards Involving Human Beings (Resolution No. 466/2012), of the National Health Council, after the submission and approval of the project through the Plataforma Brasil. The study was approved by the Research Ethics Committee of the Faculdade de Medicina da Universidade Estadual do Pará, under the opinion of the Plataforma Brasil Consubstantiated Term No. 4,041,701, and the patients signed the free and informed consent form.

The complete reports of the holter exams performed in the aforementioned period were analyzed. These exams were performed with General Electric Healthcare Seers (digital, seven electrodes, three simultaneous leads) and Cardios Light (digital, four electrodes, three simultaneous leads) recorders and analyzed with Mars and CS-550 analysis software, respectively, by a qualified physician specialist in invasive clinical electrophysiology, with 10 years of experience, according to the holter recommendations of the Brazilian Society of Cardiac Arrhythmias ${ }^{1}$.

The reports, printed on conventional A4 bond paper and digitally stored in portable document format (PDF), contained: patient identification (name, age, gender, residence, indication, comorbidities and medications in use) and cover page, with statistics summary of events (minimum, average and maximum heart rate, absolute and relative amount of supraventricular and ventricular extrasystoles, absolute amount of supraventricular and ventricular tachycardias, pauses longer than 2 seconds and ST segment changes), descriptive report and electrocardiographic traces as examples of the most relevant events, at speed $25 \mathrm{~mm} / \mathrm{s}$ and amplitude scale $1 \mathrm{mV} / 10 \mathrm{~mm}$.

The data collected from these patients, such as clinical and electrocardiographic correlation, indications, tachyarrhythmias, bradyarrhythmias, medications in use, origin, demographic data and behavior modification, were recorded in a standardized protocol for further analysis.

In the research there was inclusion of records of patients seen at the Centro Saúde Escola do Marco in Belém do Pará at greater risk of presenting electrocardiographic changes in the 24-hour holter exam, attended from September 2014 to September 2019, by the cardiology and other specialties service (medical clinic, geriatrics and neurology) at the Centro 
Saúde Escola do Marco at the Marco district, in Belém do Pará. The records of patients who did not meet the requirements during the study period were excluded from the study.

According to the nature of the variables, descriptive and analytical statistical analysis was applied. Qualitative variables were represented by frequency and percentage. All analyzes were performed using the BioEstat 5.5 software. The G test was used to verify the association between qualitative variables. Tables were constructed with the tools available in Microsoft Word ${ }^{\circledR} 2019$ and Microsoft Excel $^{\circledR} 2019$ software. Results with $\mathrm{p} \leq 0.05$ (bilateral) and 95\% significance level were considered statistically significant.

At the end of the research, all data were used for scientific purposes, aiming to provide subsidies for the implementation of policies related to cardiac pathologies with the high occurrence of these episodes in the population that aim to reduce exposure to risk factors and, with that, reduce the incidence of these diseases in the general population.

\section{RESULTS}

Of 331 patient records submitted to the 24 -hour holter, 11 were discarded due to exam failures. Thus, 320 patients were included in this study. Table 1 summarizes the sample's sociodemographic characteristics. It is observed that the majority of patients were female (64.1\%), and half were aged 60 years or over (52.2\%). One hundred eighteen (40\%) were born in Belém and the vast majority (81.5\%) also lived in Belém. Almost 66\% came from places in Belém other than the Marco district.

Table 1. Sociodemographic characteristics of patients seen at the cardiology service of the Centro Saúde Escola do Marco, from September 2014 to September 2019, Belém, Pará, Brasil*.

\begin{tabular}{lcc}
\hline Variable & Frequency & $\%$ \\
\hline Gender & 205 & 64,1 \\
Female & 115 & 35,9 \\
Male & & \\
Age (years) & 25 & 7,8 \\
7 to 19 & 35 & 10,9 \\
20 to 39 & 93 & 29,1 \\
40 to 59 & 167 & 52,2 \\
60 to 97 & & \\
Birth & 118 & 40,0 \\
Belém & 12 & 4,1 \\
Capitão Poço & 11 & 3,7 \\
Abaetetuba & 10 & 3,4 \\
Vigia & 144 & 48,8 \\
Others & & \\
\hline Residence & 256 & 81,5 \\
Belém & 27 & 8,6 \\
Ananindeua & 31 & 9,9 \\
Others & & 17,2 \\
Origin & 206 & 17,2 \\
\hline Belém & 54 & \\
Marco district & 54 & \\
Outside Belém & & \\
\hline
\end{tabular}

${ }^{*} \mathrm{p} \leq 0.05$ (bilateral). The frequencies are in decreasing order (except for age), 25 patients did not have a place of birth record, and six had no record of residence or origin.

Source: cardiology service of the Centro Saúde Escola do Marco, 2020.

In Table 2, it was found that the main indications for the exam were severity of arrhythmia (31.6\% of patients), palpitation to be clarified (22.8\%), control of arrhythmia treatment (17.5\%) and stratification of the risk of sudden death (12.2\%). 
Table 2. Indications for the holter exam ( $24 \mathrm{~h}$ ) in patients seen at the cardiology service of the Centro Saúde Escola do Marco, from September 2014 to September 2019, Belém, Pará, Brasil*.

\begin{tabular}{lcc}
\hline Recommendation & $\mathbf{n}$ & \% \\
\hline Assessment of the severity of arrhythmia & 101 & 31,6 \\
Palpitation to clarify & 73 & 22,8 \\
Control of arrhythmia treatment & 56 & 17,5 \\
Stratification of risk of sudden death - Chagas; dilated or hypertrophic cardiomyopathy & 39 & 12,2 \\
Search for cardioembolic cause of stroke & 28 & 8,8 \\
Syncope & 17 & 5,3 \\
Evaluation of the functioning of the device & 15 & 4,7 \\
None & 7 & 2,2 \\
Chest pain to clarify & 6 & 1,9 \\
Cardiotoxicity due to chemotherapy & 3 & 0,9 \\
Diabetic neuropathy and dysautonomy research & 1 & 0,3 \\
\hline
\end{tabular}

" $p \leq 0.05$ (bilateral). The percentages (decreasing) are relative to the total number of patients, and each patient could present more than one indication; Stroke. Source: Cardiology Service of the Centro Saúde Escola do Marco, 2020.

Table 3 lists the main electrocardiographic findings: supraventricular extrasystoles and ventricular extrasystoles less than $1 \%$ were the most frequent findings (reported in $71 \%$ and $57 \%$ of patients, respectively), however findings with clinical impact, either because they represent markers of severity, were they decisive in the modification of conduct with the prescription of antiarrhythmic drugs and/or oral anticoagulants, or even indication of invasive procedures or implantation of devices, occurred in: $7.5 \%$ (24 patients) for non-sustained ventricular tachycardia, $5 \%$ (16 patients) had sustained atrial fibrillation and/or atrial flutter, 5\% had supraventricular extrasystole greater than 3\%, 7\% (22 patients) had ventricular extrasystole greater than 3\%, four patients had sustained supraventricular tachycardia, nine patients had changes in the ST segment, and six had a long QT.

Other important changes, such as sustained ventricular tachycardia $(\mathrm{n}=2)$, pauses longer than 3 seconds during wakefulness $(\mathrm{n}=1)$, ventricular pre-excitation $(n=1)$, type 2 second-degree atrioventricular block $(n=2)$ and 3rd degree atrioventricular block $(n=1)$, were found less frequently. These findings reinforce the need for the availability of Holter as an auxiliary diagnostic tool in services that aim to cover the specialty of cardiology, considering the number and type of cardiovascular events verified by the referred method.

Table 3. Holter examination findings (24h) in patients seen at the cardiology service of the Centro Saúde Escola do Marco, from September 2014 to September 2019, Belém, Pará, Brasil ${ }^{*}$.

\begin{tabular}{lcc}
\hline Findings & Frequency & Percentage \\
\hline Supraventricular extrasystoles - less than 1\% & 226 & 70,6 \\
Ventricular extrasystoles - less than 1\% & 184 & 57,5 \\
Unsustained supraventricular tachycardia & 96 & 30,0 \\
1st degree atrioventricular block & 32 & 10,0 \\
Right bundle branch block & 26 & 8,1 \\
Non-sustained ventricular tachycardia & 24 & 7,5 \\
Ventricular extrasystole - greater than 3\% & 22 & 6,9 \\
Left bundle branch block & 21 & 6,9 \\
Sinus bradycardia & 19 & 5,9 \\
Sustained atrial fibrillation and/or atrial flutter & 16 & 5,0 \\
Pauses - 2 to 3 seconds & 16 & 5,0 \\
Supraventricular extrasystole - greater than 3\% & 16 & 5,0 \\
Normally functioning pacemaker & 14 & 4,4 \\
Normal & 14 & 4,4 \\
Ventricular extrasystole - between 1 and 3\% & 13 & 4,1 \\
Supraventricular extrasystole - between 1 and 3\% & 13 & 4,1 \\
ST segment changes - elevation and unevenness & 9 & 2,8 \\
Atrioventricular block of the 2nd degree Mobitz 1 & 8 & 2,5 \\
Long QT & 6 & 1,9 \\
Atrial fibrillation and/or non-sustained atrial flutter & 5 & 1,6 \\
Sustained supraventricular tachycardia & 4 & 1,3 \\
\hline
\end{tabular}

${ }^{*} \mathrm{p} \leq 0.05$ (bilateral). The percentages (decreasing) are relative to the total number of patients, and each patient could present more than one finding. Source: cardiology service of the Centro Saúde Escola do Marco, 2020. 
The drugs most frequently reported by patients (Table 4) correspond to the most common risk factors (Fig. 1): systemic arterial hypertension (SAH) (57\%), dyslipidemia (33\%), diabetes mellitus (12\%), insufficiency (12\%), stroke sequelae (7\%) and coronary disease (5\%). The silent nature of the first two and progressive and/or recurrent of the last three makes holter necessary as a method for assessing dysautonomies (diabetes mellitus), risk stratification (heart failure) and cardioembolic cause (stroke) research.

Table 4. Medicines in use by patients seen at the cardiology service of the Centro Saúde Escola do Marco, from September 2014 to September 2019, Belém, Pará, Brasil*.

\begin{tabular}{lcc}
\hline Medication & Frequency & \% \\
\hline Others & 121 & 37,8 \\
ARB & 117 & 36,6 \\
Statin & 97 & 30,3 \\
Platelet antiaggregant & 83 & 25,9 \\
Beta blocker & 72 & 22,5 \\
None/unknown & 64 & 20,0 \\
Thiazide diuretic & 59 & 18,4 \\
ACE & 48 & 15,0 \\
CCB & 46 & 14,4 \\
Potassium sparing diuretic & 38 & 11,9 \\
Class 2 antiarrhythmic & 32 & 10,0 \\
Class 3 antiarrhythmic & 20 & 6,3 \\
Anticoagulant & 14 & 4,4 \\
Loop diuretic & 14 & 4,4 \\
Nitrate or trimatazidine & 13 & 4,1 \\
Other antiarrhythmic drugs & 10 & 3,1 \\
Fibrate & 9 & 2,8 \\
Class 1 antiarrhythmic & 9,8 \\
Class 4 antiarrhythmic & 9 & 1,3 \\
Direct vasodilator & 4 & 0,9 \\
\hline
\end{tabular}

${ }^{*} \mathrm{p} \leq 0.05$ (bilateral). The percentages (decreasing) are relative to the total number of patients, and each patient could use more than one medication; ARB: angiotensin receptor blocker; ACE: angiotensin II converting enzyme inhibitor; CCB:Calcium channel blocker

Source: cardiology service of the Centro Saúde Escola do Marco, 2020.

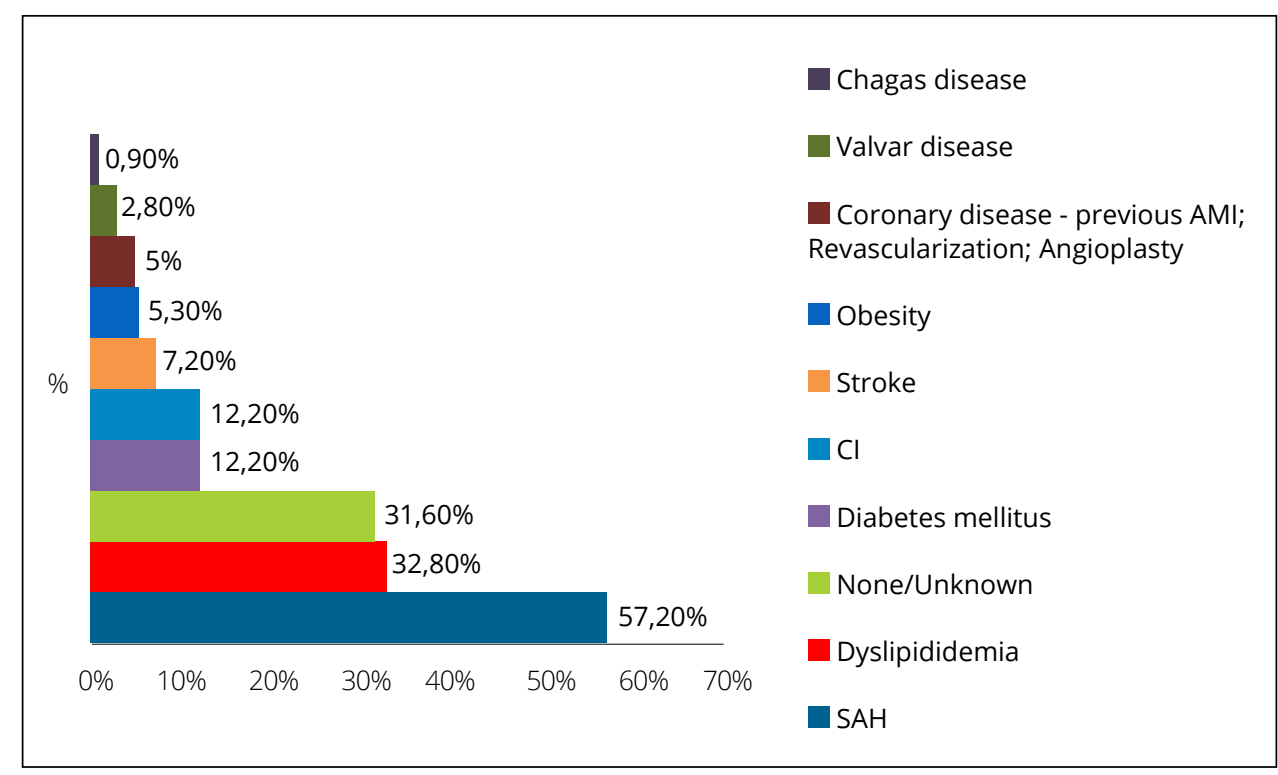

Figure 1. Percentage distribution of risk factors of patients seen at the cardiology service of the Centro Saúde Escola do Marco, from September 2014 to September 2019, Belém, Pará, Brasil. AMI: acute myocardial infarction; CI:Cardiac insufficiency; DM: diabetes mellitus; SAH: systemic arterial hypertension.

Source: cardiology service of the Centro Saúde Escola do Marco, 2020. 
Among the electrocardiographic findings with statistical significance considering the sample itself, we have the presence of symptomatic supraventricular extrasystole (agreement between the symptoms reported in the diary and the presence of extrasystoles) when it has a frequency greater than $3 \%$ in the 24 hours of recording, almost three times more recurrent (13 vs. $38 \%, \mathrm{p}<0.001)$.

There were no patients with divergence (normal electrocardiogram during symptoms) among those with supraventricular extrasystoles greater than $3 \%$, but this divergence occurred in $33 \%$ of patients with extrasystoles less than 3\% ( $\mathrm{p}<0.001)$ (Table 5). A similar result occurred when ventricular extrasystoles were assessed (symptomatic agreement slightly more than twice as frequent among those with an incidence greater than $3 \%$ in the 24 hours 13 vs. $27 \%$ - and more common symptomatic divergence among those with an incidence less than $3 \%$ in the 24 hours - 33 vs. 9\%) (Table 6).

Table 5. Associations of supraventricular extrasystoles (greater than 3\%) in patients seen at the cardiology service of the Centro Saúde Escola do Marco, from September 2014 to September 2019, Belém, Pará, Brasil*.

\begin{tabular}{|c|c|c|c|}
\hline \multirow{2}{*}{ Variable } & \multicolumn{3}{|c|}{ Supraventricular extrasystoles greater than $3 \%$} \\
\hline & No $(n=304)$ & Yes $(n=16)$ & $\mathrm{p}$ value \\
\hline Correlation & & & $<0,001$ \\
\hline Absent & $164(53,9)$ & $10(62,5)$ & \\
\hline Agreeing & $40(13,2)^{* *}$ & $6(37,5) \dagger$ & \\
\hline Divergent & $100(32,9) \dagger$ & $0(0)^{\star *}$ & \\
\hline Age (years) & & & 0,609 \\
\hline 7 to 19 & $23(7,6)$ & $2(12,5)$ & \\
\hline 20 to 39 & $34(11,2)$ & $1(6,3)$ & \\
\hline 40 to 59 & $90(29,6)$ & $3(18,8)$ & \\
\hline 60 to 97 & $157(51,6)$ & $10(62,5)$ & \\
\hline Age (years) & & & 0,816 \\
\hline 79 or less & $281(92,4)$ & $14(87,5)$ & \\
\hline 80 or more & $23(7,6)$ & $2(12,5)$ & \\
\hline Age (years) & & & 0,553 \\
\hline 59 or less & $147(48,4)$ & $6(37,5)$ & \\
\hline 60 or more & $157(51,6)$ & $10(62,5)$ & \\
\hline
\end{tabular}

${ }^{*} \mathrm{p}<0,001$. The variables are represented as $\mathrm{n}(\%)$, relative to the column total. In all cases, the $\mathrm{G}$ test was used; ${ }^{* *}$ the observed frequency was lower than what would be expected at random; † the observed frequency was higher than expected.

Source: cardiology service of the Centro Saúde Escola do Marco, 2020.

Table 6. Associations of ventricular extrasystoles (greater than 3\%) in patients seen at the cardiology service of the Centro Saúde Escola do Marco, from September 2014 to September 2019, Belém, Pará, Brasil*.

\begin{tabular}{lccc}
\hline \multirow{2}{*}{ Variable } & \multicolumn{3}{c}{ Ventricular extrasystoles greater than 3\% } \\
\cline { 2 - 4 } & No $(\mathbf{n}=\mathbf{2 9 8 )}$ & Yes $(\mathbf{n}=\mathbf{2 2})$ & p value \\
\hline Correlation & & & 0,022 \\
Absent & $160(53,7)$ & $14(63,6)$ & $6(27,3)$ \\
Agreeing & $40(13,4)$ & $2(9,1)^{* *}$ & \\
Divergent & $98(32,9) \dagger$ & & \\
\hline
\end{tabular}

${ }^{*} p<0,001$. The variables are represented as $n(\%)$, relative to the column total. The G test was used; ** the observed frequency was lower than what would be expected at random; $\dagger$ the observed frequency was higher than expected.

Source: cardiology service of the Centro Saúde Escola do Marco, 2020.

A significant association was found between non-sustained ventricular tachycardia and the presence of heart failure (17.9\% of non-sustained ventricular tachycardia - NSVT - among patients with heart failure, $p=0.038$ ) (Table 7). In addition to the presence of an association between the electrocardiographic finding of atrial fibrillation and/or atrial flutter and the male gender $(60 \%, \mathrm{p}=0.043)$, it is also important to highlight the low rate of anticoagulation observed in patients with arterial fibrillation (20\%) (Table 8). 
Table 7. Associations of non-sustained ventricular tachycardia in patients seen at the cardiology service of the Centro Saúde Escola do Marco, no período de setembro de 2014 a setembro de 2019, Belém, Pará, Brasil ${ }^{\star}$.

\begin{tabular}{|c|c|c|c|}
\hline \multirow{2}{*}{ Variable } & \multicolumn{3}{|c|}{ Non-sustained ventricular tachycardia } \\
\hline & No $(n=296)$ & Yes $(n=24)$ & $\mathrm{p}$ value \\
\hline Cardiac insufficiency & & & 0,038 \\
\hline No & $264(89,2) \dagger$ & $17(70,8)^{* *}$ & \\
\hline Yes & $32(10,8)^{\star *}$ & $7(29,2) \dagger$ & \\
\hline Coronary heart disease\# & & 0,778 & \\
\hline No & $281(94,9)$ & $23(95,8)$ & \\
\hline Yes & $15(5,1)$ & $1(4,2)$ & \\
\hline Age (years) & & & 0,808 \\
\hline 7 to 19 & $22(7,4)$ & $3(12,5)$ & \\
\hline 20 to 39 & $33(11,1)$ & $2(8,3)$ & \\
\hline 40 to 59 & $87(29,4)$ & $6(25,0)$ & \\
\hline 60 to 97 & $154(52,0)$ & $13(54,2)$ & \\
\hline Age (years) & & & 0,760 \\
\hline 79 or less & $273(92,2)$ & $22(91,7)$ & \\
\hline 80 or more & $23(7,8)$ & $2(8,3)$ & \\
\hline Age (years) & & & 0,992 \\
\hline 59 or less & $142(48,0)$ & $11(45,8)$ & \\
\hline 60 or more & $154(52,0)$ & $13(54,2)$ & \\
\hline
\end{tabular}

${ }^{*} p<0,001$. The variables are represented as $n(\%)$, relative to the column total. In all cases, the $\mathrm{G}$ test was used; ${ }^{* *}$ the observed frequency was lower than what would be expected at random; † the observed frequency was higher than expected; \#previous myocardial infarction; revascularization; angioplasty. Source: cardiology service of the Centro Saúde Escola do Marco, 2020.

Table 8. Association of atrial fibrillation and/or atrial flutter in patients seen at the cardiology service of the Centro Saúde Escola do Marco, from September 2014 to September 2019, Belém, Pará, Brasil*.

\begin{tabular}{|c|c|c|c|}
\hline \multirow{2}{*}{ Variable } & \multicolumn{3}{|c|}{ Atrial fibrillation and/or flutter } \\
\hline & No $(n=300)$ & Yes & $\mathrm{p}$ value \\
\hline Stroke & & & 0,956 \\
\hline No & $278(92,7)$ & $19(95)$ & \\
\hline Yes & $22(7,3)$ & $1(5)$ & \\
\hline Cardiac insufficiency & & 0,965 & \\
\hline No & $26(87,7)$ & $18(90)$ & \\
\hline Yes & $37(12,3)$ & $2(10)$ & \\
\hline Anticoagulants & & & 0,020 \\
\hline No & $290(96,7) \dagger$ & $16(80)^{* *}$ & \\
\hline Yes & $10(3,3)^{\star *}$ & $4(20) \dagger$ & \\
\hline Gender & & & 0,043 \\
\hline Female & $197(65,7) \dagger$ & $8(40)^{* *}$ & \\
\hline Male & $103(34,3)^{\star \star}$ & $12(60) \dagger$ & \\
\hline Age (years) & & & 0,146 \\
\hline 7 to 19 & $25(8,3)$ & $0(0)$ & \\
\hline 20 to 39 & $34(11,3)$ & $2(8,3)$ & \\
\hline 40 to 59 & $88(29,3)$ & $5(25)$ & \\
\hline 60 to 97 & $153(51)$ & $14(70)$ & \\
\hline Age (years) & & & 0,0452 \\
\hline 79 or less & $278(92,7)$ & $17(85)$ & \\
\hline 80 or more & $22(7,3)$ & $3(15)$ & \\
\hline Age (years) & & & 0,152 \\
\hline 59 or less & 147 (49) & $6(30)$ & \\
\hline 60 or more & $153(51)$ & $14(70)$ & \\
\hline
\end{tabular}

" $p<0,001$. The variables are represented as $n(\%)$, relative to the column total. In all cases, the $G$ test was used; ** the observed frequency was lower than what would be expected at random; $†$ the observed frequency was higher than expected.

Source: cardiology service of the Centro Saúde Escola do Marco, 2020. 


\section{DISCUSSION}

In Table 2, it was found that the main indications for the exam were severity of arrhythmia, palpitation to be clarified, control of the treatment of arrhythmia and stratification of sudden death. This result is somewhat compatible with the research by Brescia et al. ${ }^{5}$, in which the presence of ventricular arrhythmia and the risk of sudden death in the population were described, both related to ventricular dysfunction with mortality of $13 \%$, and in $6 \%$ of cases sudden death occurred. Therefore, it is healthy to offer this type of service to the units that provide cardiological care as a diagnostic support tool, in a context of complementing specialized care.

The drugs in use by patients in our series and reported on the day of the examination were grouped in Table 4. It can be seen that the most used were angiotensin receptor blockers (ARBs) or angiotensin II-converting enzyme inhibitors (ACE inhibitors) ( respectively, 37 and 15\%, in a total of 52\% of patients). Statins were in use by $30.3 \%$ of patients; antiplatelet agents, in use by $25.9 \%$; and thiazide diuretics, in use by $20 \%$ of them. A fifth (20\%) of the participants did not report the use of specific medications.

Thus, it is worth mentioning that the use of ACE inhibitors or ARBs can significantly reduce cardiovascular morbidity and mortality, in addition to a $10 \%$ reduction in cardiovascular events and a $17 \%$ reduction in cardiovascular mortality ${ }^{6}$. In our series, this finding demonstrates that the population studied under treatment with the said group of drugs constitutes a special group with a higher risk for cardiovascular events.

Another fact that is consistent with the scenario found is the note that the main guidelines recommend several drug therapies for the classic treatment of heart failure, which influences the prescription of these drugs, according to their etiology and intensity.

Among these drugs, there are angiotensin receptor blockers (ARBs), which will act directly on the renin-angiotensinaldosterone system (RAAS-8 A), promoting cardiovascular homeostasis. In addition, they have some advantages, such as high tolerability, when compared to other classes, bringing functional and clinical benefits to patients with heart failure ${ }^{7}$.

There is an understanding of the importance of treatment to prevent cardiovascular complications in hypertensive patients, with ACEI and ARB being the most used drugs. These articles corroborate the effectiveness of ACE inhibitors and $A R B s$ in reducing post-AMI mortality. Nevertheless, there are authors in the literature who argue that the ACE inhibitor is more effective than the ARB in reducing the risk of AMI and / or other cardiovascular complications in hypertensive patients, with the latter being preferable to the latter. We consider that, unfortunately, despite the contrary evidence, the clinical practice applied to our sample showed a proportion of patients in little more than twice the use of ARBs, when they should be an alternative to the use of ACEI.

These drug findings most frequently reported by patients correspond to the most commonly found risk factors (Fig.1): systemic arterial hypertension, dyslipidemia, diabetes mellitus, heart failure, stroke sequel and coronary heart disease. The silent nature of the first two and progressive and / or recurrent of the last three makes holter necessary as a method for assessing dysautonomies (diabetes mellitus), risk stratification (heart failure) and cardioembolic cause research (stroke).

This result refers to the scenario that, the closer to the base of the pyramid, the greater the impact of preventive, diagnostic and therapeutic measures on the general population. It has been observed that the segment of clinical interventions is in a higher position. That is, even if the interventions are carried out effectively, the total impact is, at most, average. Among the reasons are cited deficiency in access to medical care, poor adherence to treatment, low efficacy of certain therapeutic measures, in addition to the difficulty in creating control and prevention strategies for asymptomatic diseases, such as Systemic Arterial Hypertension, dyslipidemia and some heart diseases, including cardiac arrhythmias ${ }^{8,9}$.

In Brazil, cardiovascular diseases have a high mortality rate, and atherosclerosis (which causes AMI) is a chronic inflammatory disease of multifactorial origin that occurs in response to an endothelial aggression, affecting the intimate layer of medium and large caliber arteries. The formation of atherosclerotic plaque begins with aggression to the vascular endothelium because of several risk factors, such as dyslipidemia, arterial hypertension or smoking 9 .

It is inferred that the scenario found in the present research is in accordance with the findings of the national literature, as well as it is known that hypertension, diabetes and obesity are diseases also defined as risk factors for other cardiovascular 
events, such as coronary artery disease. Such risk factors, together with dyslipidemia, smoking, stress, physical inactivity, inadequate diet and alcoholism, are responsible for more than $90 \%$ of the risk attributable to cardiovascular diseases ${ }^{10}$.

Among the electrocardiographic findings, there is a strong association of symptomatic supraventricular and ventricular extrasystoles and a frequency> $3 \%$ in 24 hours. This suggests that this cut-off criterion can be used systematically in other studies to be validated as an important reference value in clinical practice. In an attempt to compare exercise testing with dynamic electrocardiography in the detection of complex ventricular arrhythmias, in the various stages of myocardial impairment of chronic Chagas heart disease, Pedrosa et al. ${ }^{11}$ detected through the holter the presence of arrhythmia in $10 \%$ of the studied individuals, including non-sustained ventricular tachycardia. The same researchers identified such arrhythmias in only $1 \%$ of the patients classified as the lowest risk, so that the possible evolutionary importance of ventricular arrhythmias, especially in those without apparent heart disease, is still unknown, but the authors recommend clinical monitoring and, eventually, holter in those patients with clinical suspicion of disease progression ${ }^{11}$.

In the same sense, there is another statement that, in general, in the literature, there is agreement between the occurrence of 10 or more ventricular extrasystoles per hour during outpatient monitoring, and a subgroup with a mortality rate of 2.5 to four times greater than those with absence or low occurrence of these arrhythmias. NSVT, which occurs in $12 \%$ of convalescent AMI patients, is related to mortality 4.2 times higher compared to the subgroup without this arrhythmia. In our series, this finding was found in a general proportion of $12.2 \%$ (Table 6), being more frequent in those with heart failure - almost triple in this group of patients ( 29 vs. $11 \%, p=0.038$ ). However, although the specificity and negative predictive value of such findings are high, exceeding $90 \%$, sensitivity and positive predictive value remain low, from 5 to $15 \%$ for sudden death and between 11 and $32 \%$ for total death ${ }^{12}$.

This result can be corroborated by the statement that holter monitoring is a valuable diagnostic tool in the detection of patients with non-sustained ventricular tachycardia ${ }^{13}$.

Some studies indicate that unsustainable ventricular tachycardia in chagasic patients using the holter $(24 \mathrm{~h})$ was correlated with decreased life expectancy. In this study there was a greater reduction in life expectancy due to NSVT when associated with cardiomegaly ${ }^{11,13,14}$.

The prevalence of atrial fibrillation found in a population submitted for reasons not selected for 24-hour electrocardiographic monitoring is $2.5 \%$, and the total prevalence of atrial fibrillation (AF) and atrial flutter is $12.4 \%$. Paroxysmal atrial fibrillation affects younger patients than the persistent or permanent form, being less dependent on risk factors, such as SAH. Correlates with significantly higher percentages of stroke ${ }^{3}$. Our study found a record of $5 \%$ of patients with fibrillation or sustained atrial flutter, showing that they were in agreement with the other studies and revealing a number of patients with cardioembolic risk, reinforced by the finding of only $20 \%$ of these patients using anticoagulant therapy.

It is also mentioned that in many patients, despite repeated and prolonged electrocardiographic analyzes, AF cannot be identified, but other types of cardiac arrhythmias are diagnosed. A gap still present for the identification of risk factors for cardioembolic ischemic stroke is the knowledge of what types of cardiac arrhythmias have thrombogenic potential and which changes in electrocardiographic tracings may suggest the presence of paroxysmal AF. Some studies report the relationship between frequent early atrial beats caught on a 24-hour holter electrocardiogram and the increased risk of paroxysmal $\mathrm{AF}^{15}$.

The low percentage of patients with a diagnosis of AF confirmed by the holter using oral anticoagulants is explained by the fact that the majority of patients with this finding in this series did not know they have this arrhythmia until the exam was performed, which is indicated as a diagnostic method, and not as treatment control. The finding of occasional AF was also directly proportional to age and showed a significant correlation between male subjects.

Our study was unable to demonstrate $\mathrm{AF}$ as a statistically significant cardioembolic cause among patients with stroke sequelae $(\mathrm{p}=\mathrm{ns})$, however a higher frequency of this arrhythmia in men (60 vs.34\%, $\mathrm{p}=0.04)$ and tendency to range older age (presence of AF in elderly 70 vs. $51 \%$ in non-elderly, $\mathrm{p}=0.146$ ) were found, in line with findings from large classic clinical trials. It was also found that $\mathrm{AF}$ and/or atrial flutter were significantly associated with the use of anticoagulants $(p=0.020)$, which is explained by the thromboembolic nature of this disease and by its respective necessary treatment ${ }^{16}$.

In view of this scenario, the importance of using a 24-hour holter in the systematic detection of patients with arrhythmias is confirmed, which present themselves as a significant public health problem and whose early diagnosis is essential in the 
definition and therapeutic success. It is relevant to add that cardiovascular diseases are significant in the scope of public health, as they are the main causes of morbidity and mortality in Brazil, with a high socioeconomic impact on health systems.

Therefore, a better understanding of the methods of treatment and prevention of cardiovascular diseases, as well as the role of the holter $(24 \mathrm{~h})$ in the identification of heart problems, is of great relevance to the area of public health, both with regard to improving quality in terms of medication budgets and the health care system for this population.

In line with the aforementioned studies, it can be said that, although other modern devices have internal memories and are capable of storing events (registered by the patient or considering pre-selected parameters), the 24-hour holter still plays an important role in identifying patients with electrocardiographic changes.

\section{CONCLUSIONS}

The 24-hour holter is, therefore, still an extremely useful tool to assess suspicious symptoms of cardiac origin and the documentation of diverse electrocardiographic events, either for diagnostic purposes or for therapeutic control purposes. Despite the emergence and implementation of alternative and even more efficient monitoring techniques, holter monitoring still remains an indication of the first line of diagnostic support for various heart diseases, due to the relatively low cost and being non-invasive. In relation to the advantages, it is shown to be reasonable to adopt this technique to determine the potential changes of the specific parameters of the cardiac rhythm through the recording of the 24-hour electrocardiogram.

Although it has the potential to be performed in any outpatient unit, its implementation in the Unified Health System (Sistema Único de Saúde-SUS) network in the city of Belém is still restricted, considering that the 24-hour holter has an important role in identifying patients with electrocardiographic changes on an outpatient basis, even in a Basic Health Unit (Unidade Básica de Saúde-UBS), given the severity of the population studied and the findings of this study, hidden (such as the low rate of anticoagulation, because of the lack of prior diagnosis) or unclear (such as palpitations associated with frequent extrasystole). The clinical severity of the population studied was indirectly assessed by the findings, such as ventricular tachycardia, AF, advanced blocks and pauses. The restriction of the geographical scope of a UBS does not envisage the scarcity of professionals qualified in this diagnostic method in the entire municipality of Belém, making it difficult for patients with an indication to perform it, culminating in a hospital-centered care model. Decentralization, even with remote assessment resources, and the definitive implementation at the State University of Pará of a municipal reference service integrated into the service network are alternatives that can reduce this repressed demand.

\section{REFERENCES}

1. Lorga Filho A, Cintra FD, Lorga A, Grupi CJ, Pinho C, Moreira DAR, et al. Recomendações da sociedade brasileira de arritmias cardíacas para serviços de holter. Arq Bras Cardiol [Internet]. 2013 [acessado em 31 ago. 2020];101(2):101-5. Disponível em: http:// www.scielo.br/scielo.php?script=sci_arttext\&pid=S0066-782X2013002800002\&lng=en. https://doi.org/10.5935/abc.20130164

2. Hendrikx T, Rosenqvist M, Wester $P$, Sandström $H$, Hörnsten R. O registro intermitente de ECG curto é mais eficaz do que o Holter ECG de 24 horas na detecção de arritmias. BMC Cardiovasc Disord. 2014;14:41. https://doi.org/10.1186/1471-2261-14-41

3. Primo J, Gonçalves H, Macedo A, Russo P, Monteiro T, Guimarães J, et al. Prevalence of paroxysmal atrial fibrillation in a population assessed by continuous 24-hour monitoring. Rev Port Cardiol. 2017;36(7-8):535-46. https://doi.org/10.1016/j.repc.2016.11.005

4. Brasil. Ministério da Saúde. Informações de saúde TABNET: Estatísticas vitais, 2018. DATASUS [Internet]. Brasil: Ministério da Saúde [acessado em 19 ago. 2020]. Disponível em http://tabnet.datasus.gov.br

5. Brescia ST, Rossano JW, Pignatelli R, Jefferies JL, Price JF, Decker JA, et al. Mortality and sudden death in pediatric left ventricular noncompaction in a tertiary referral center. Circulation. 2013;127(22):2202-8. https://doi.org/10.1161/circulationaha.113.002511

6. Lima MM, Nunes CP. Eficácia do uso de IECA/BRA na diminuição da mortalidade pós infarto do miocárdio em hipertensos com complicações cardiovasculares. Rev Med Fam Saúde Mental. 2019;1(1):46-55. 
7. Montenegro EG, Medeiros JO, Ribeiro RC, Soares Júnior JL, Sousa MNA. Avaliação da Eficácia de Bloqueadores dos Receptores da Angiotensina como Tratamento para a Insuficiência Cardíaca. Saúde Foco. 2016;3(2):93-104. http://dx.doi.org/10.12819/ rsf.2016.3.2.7

8. Santos DR. O papel do enfermeiro no atendimento emergencial ao paciente vítima de infarto agudo do miocárdio na sala vermelha: uma revisão e literatura [monografia]. Florianópolis: Universidade Federal de Santa Catarina; 2014.

9. Faludi AA, Izar MCO, Saraiva JFK, Chacra APM, Bianco HT, Afiune Neto A, et al. Atualização da Diretriz Brasileira de Dislipidemias e Prevenção da Aterosclerose - 2017. Arq Bras Cardiol. 2017;109(2 Supl. 1):1-76.

10. Borges AP. Desenvolvimento de um sistema holter de eletrocardiograma [trabalho de conclusão de curso]. Campo Mourão: Universidade Tecnológica Federal do Paraná; 2018.

11. Pedrosa RC, Campos MCD. Teste ergométrico e o Holter de 24 horas na detecção de arritmias ventriculares complexas em diferentes estádios da cardiopatia chagásica crônica. Rev Soc Bras Med Trop. 2004;37(5):376-83. https://doi.org/10.1590/S003786822004000500002

12. Brito FS. Eletrocardiografia ambulatorial: sistema holter. Diretriz para aplicação do holter no pós-infarto agudo do miocárdio: avaliação e estratificação. Diagnósticos em Cardiologia. 2009;41(12).

13. Katritsis DG, Siontis GC, Camm AJ. Prognostic significance of ambulatory ECG monitoring for ventricular arrhythmias. Prog CardiovasC Dis. 2013;56(2):133-42. https://doi.org/10.1016/j.pcad.2013.07.005

14. Corrêa RS. Importância do eletrocardiograma de repouso, de alta resolução e do Holter de 24 horas em pacientes com miocárdio não compacto: relação com os achados do ecocardiograma e ressonância magnética cardíaca [tese]. São Paulo: Universidade de São Paulo; 2014.

15. Silva HC. Alterações evidenciadas no eletrocardiograma, ecocardiograma e holter de $24 \mathrm{~h}$ nos pacientes com acidente vascular cerebral de mecanismo indefinido [trabalho de conclusão de curso]. Fortaleza: Hospital Geral de Fortaleza; 2018.

16. Corley SD, Epstein AE, DiMarco JP, Domanski MJ, Geller N, Greene HL, et al. Relationships between sinus rhythm, treatment, and survival in the Atrial Fibrillation Follow-Up Investigation of Rhythm Management (AFFIRM) Study. Circulation. 2004;109(12):1509-13. https://doi.org/10.1161/01.cir.0000121736.16643.11 